\title{
HARMONIC MITIGATION FOR POWER QUALITY IMPROVEMENT
}

\author{
Jeel Contractor ${ }^{1}$, P.N.Kapil ${ }^{2}$, Bhavin Shah ${ }^{3}$ \\ ${ }^{I}$ M.Tech (PEMD) ,EE, Nirma University, Ahmedabad, India \\ ${ }^{2}$ Assistant Professor, EE, Nirma University, Ahmedabad, India \\ ${ }^{3}$ Director, PQS Electrolink (I) Pvt. Ltd. , Ahmedabad, India
}

\begin{abstract}
In every industries non-linear load such as single-phase diode rectifier, converters, inverters, low voltage power supplies, SMPS, personal computers etc are exists. In every three-phase system the lowest and significant order of harmonic will be $5^{\text {th }}$ harmonic after the fundamental. This harmonics incurs losses in the form of heat dissipation and also contribute to eddy currents and core losses. This extra heat have significant impact in reducing the operating life of electrical instrument especially transformer insulation. This paper provides information on harmonic mitigation techniques for power quality improvement.
\end{abstract}

Keywords: Harmonics, power quality, harmonic mitigation, De-tuned filter

\section{INTRODUCTION}

In the recent time, there exist many different non-linear loads in the different kinds of industries. Due to the non-linearity of the loads it injects harmonics in the system and deteriorate the power factor of the entire system. The first solution is often possible by phase-shifting of the transformers and/or the control of converter bridges or by the use of switching devices with turn-off capability. External harmonic compensation can be achieved by means of filters [1]. The harmonic components have large current magnitudes. The harmonics generated will be divided into three types that is positive sequence harmonics, negative-sequence harmonics and zero-sequence harmonics. The positive-sequence harmonics current are the current harmonic components such as $7^{\text {th }}, 13^{\text {th }}, 19^{\text {th }}$ and negative-sequence harmonics current such as $5^{\text {th }}, 11^{\text {th }}, 17^{\text {th }}$ that is excessive in phase line which increase the THD (Total Harmonic Distortion) of the system. While, zero-sequence harmonics current that is triplen harmonics such as $3^{\text {th }}, 9^{\text {th }}, 15^{\text {th }}$ will flows through the neutral wire and may cause overheating on that wire.

\section{HARMONICS}

Harmonic frequencies are integral multiples of the fundamental supply frequency, i.e. for a fundamental of 50 $\mathrm{Hz}$, the third harmonic would be $150 \mathrm{~Hz}$ and the fifth harmonic would be $250 \mathrm{~Hz}$.

\subsection{Types of Equipment that Generate Harmonics[2]}

In the industries there are two types of loads. (1) Linear (2) Non-linear. Linear loads will absorb the power linearly. And the current waveforms are also sinusoidal. Whereas nonlinear loads will absorb power in non-linear fashion and the current waveform is not sinusoidal but it is distorted. Harmonic load currents are generated by all non-linear loads. These include: Single phase loads, e.g. Switched mode power supplies (SMPS), Electronic fluorescent lighting ballasts, Small uninterruptable power supplies (UPS) units.

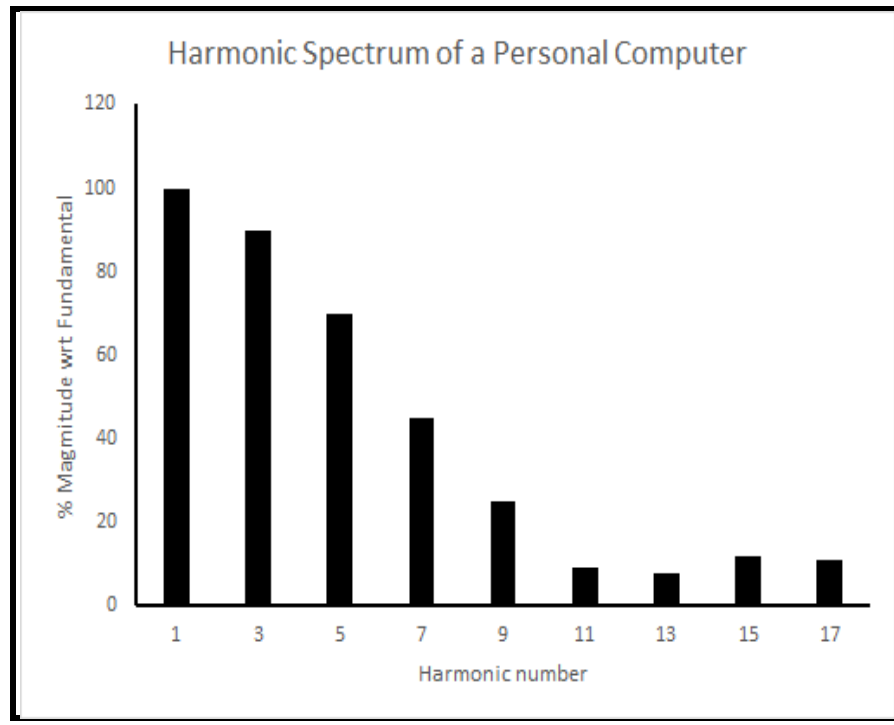

Fig. 1 Harmonic spectrum of a personal computer

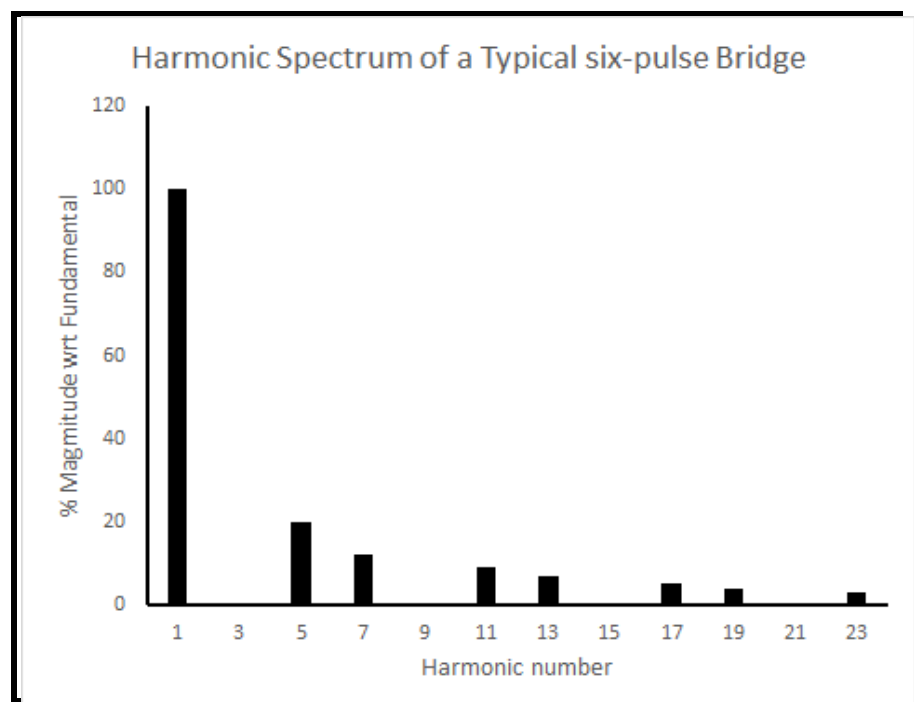

Fig. 2 harmonic spectrum of a typical six-pulse Bridge 


\subsection{Harmonic Problems within the Installation}

There are several common problem areas caused by harmonics :

\section{Problems caused by harmonic currents}

1. Overloading of neutrals.

2. Overheating of transformers

3. Nuisance tripping of circuit breakers.

4. Over-stressing of power factor correction capacitors.

5.Skin effect

\section{Problems caused by harmonic voltages}

1. Voltage distortion.

2. Induction motors

3. Zero-crossing noise

\subsection{Effect of Harmonics}

- $\quad$ Tripping of circuit breakers and fuses

- $\quad$ Overloading / decrease of life time of transformer

- Overloading of transformer

- $\quad$ Losses in distribution equipment

- $\quad$ Excessive currents in the neutral conductor

- Measurements error in the metering system

\subsection{Harmonic Mitigation Techniques}

Table 1: HMTs and their main features [3][7]

\begin{tabular}{|c|c|}
\hline HMT & Main Features \\
\hline $\begin{array}{l}\text { Phase } \\
\text { multiplication }\end{array}$ & $\begin{array}{l}\text { Effective to reduce low order } \\
\text { harmonics as long as there is a } \\
\text { balanced load }\end{array}$ \\
\hline Passive filters & $\begin{array}{l}\text { Improve power factor, reduce } \\
\text { high-frequency harmonics, large } \\
\text { size. If tuning reactors are not } \\
\text { used, instability may occurs due to } \\
\text { parallel resonance with the source } \\
\text { inductance. Performance depends } \\
\text { on the source impedance which is } \\
\text { usually not known accurately and } \\
\text { can vary with system changes. } \\
\text { Not for } \\
\text { cycloconverters. }\end{array}$ \\
\hline Active filters & $\begin{array}{l}\text { Improved power factor. Output } \\
\text { current can be controlled. Provide } \\
\text { stable operation against ac source } \\
\text { impedance variations, and fast } \\
\text { response irrespective of the order } \\
\text { and magnitude of the harmonics. } \\
\text { Appropriate for cycloconverter. } \\
\text { Initial and running costs are } \\
\text { usually higher than passive filters }\end{array}$ \\
\hline $\begin{array}{l}\text { Harmonic } \\
\text { Injection }\end{array}$ & $\begin{array}{l}\text { Takes care of uncharacteristic } \\
\text { harmonics. } \\
\text { System impedance is no part of the } \\
\text { design criteria, may give rise to } \\
\text { low-order harmonics. }\end{array}$ \\
\hline
\end{tabular}

\begin{tabular}{|l|l|}
\hline HMT with & $\begin{array}{l}\text { Capable of obtaining harmonic } \\
\text { reduction of less than } 1 \% \text { of the } \\
\text { fundamental. Programmable to } \\
\text { eliminate specific harmonics. }\end{array}$ \\
\hline
\end{tabular}

\section{POWER QUALITY ANALYSIS}

The first step in solving harmonic related problems is to perform an analysis to determine the specific needs of your electrical distribution system. To determine capacitor and filter requirements, it is necessary to establish the impedance of the supply network and the value of each harmonic current. Capacitor, reactor and filter bank equipment are then specified under very detailed and stringent computer analysis to meet your needs.

Analysis is carried out at Rashtriya Metal Industries Ltd., sarigan GIDC, Vapi. It is basically Metal Industry. Here loads are generally AC and DC - small and medium sized drives and normal lighting load. The transformer specifications are 3.15MVA, 11/0.433 KV, 400Amp.

\subsection{Readings}

Graph of power factor, Voltage THD and Current THD of main incomer are shown in below figures. 


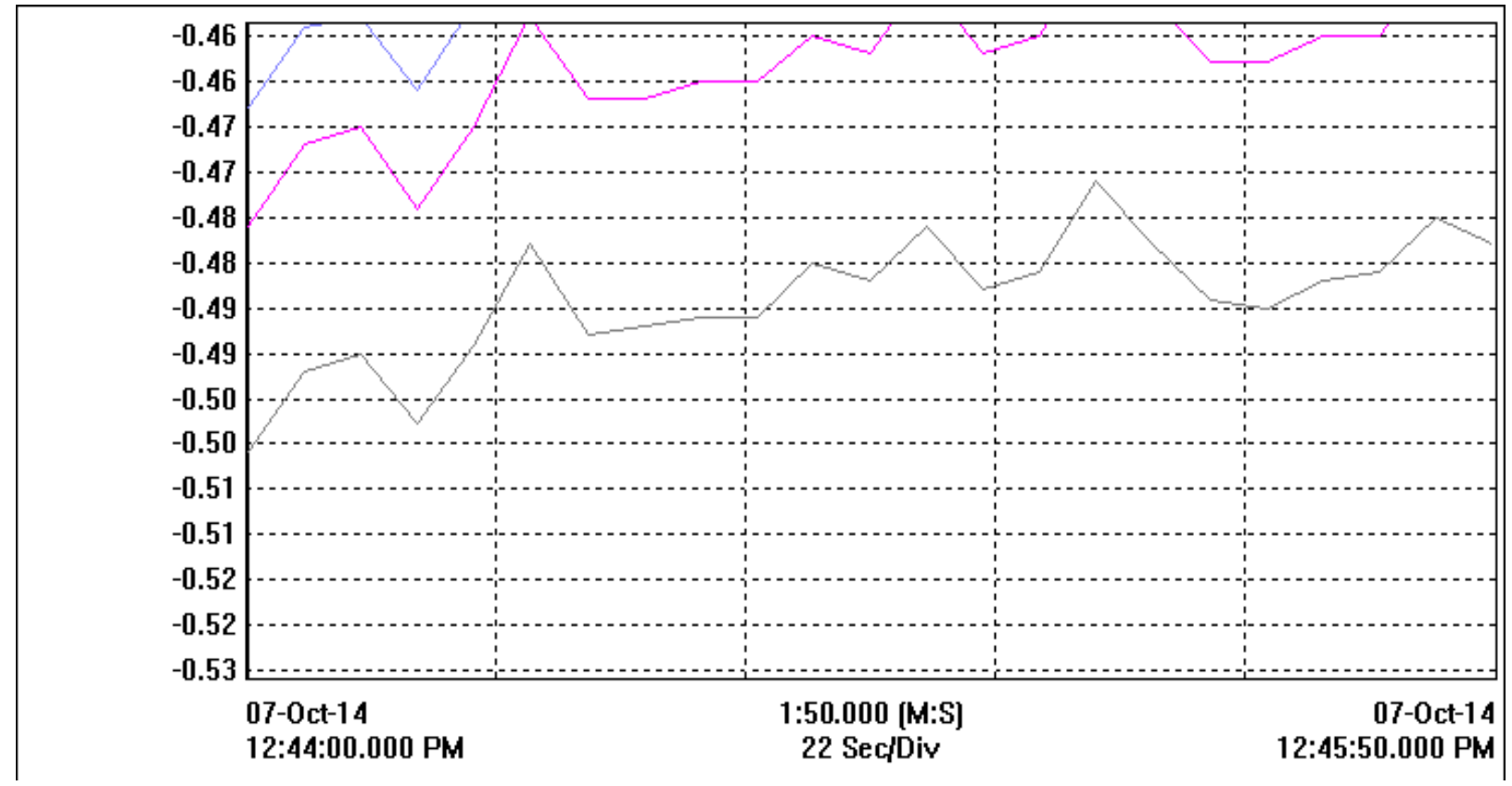

Fig. 3 Power factor

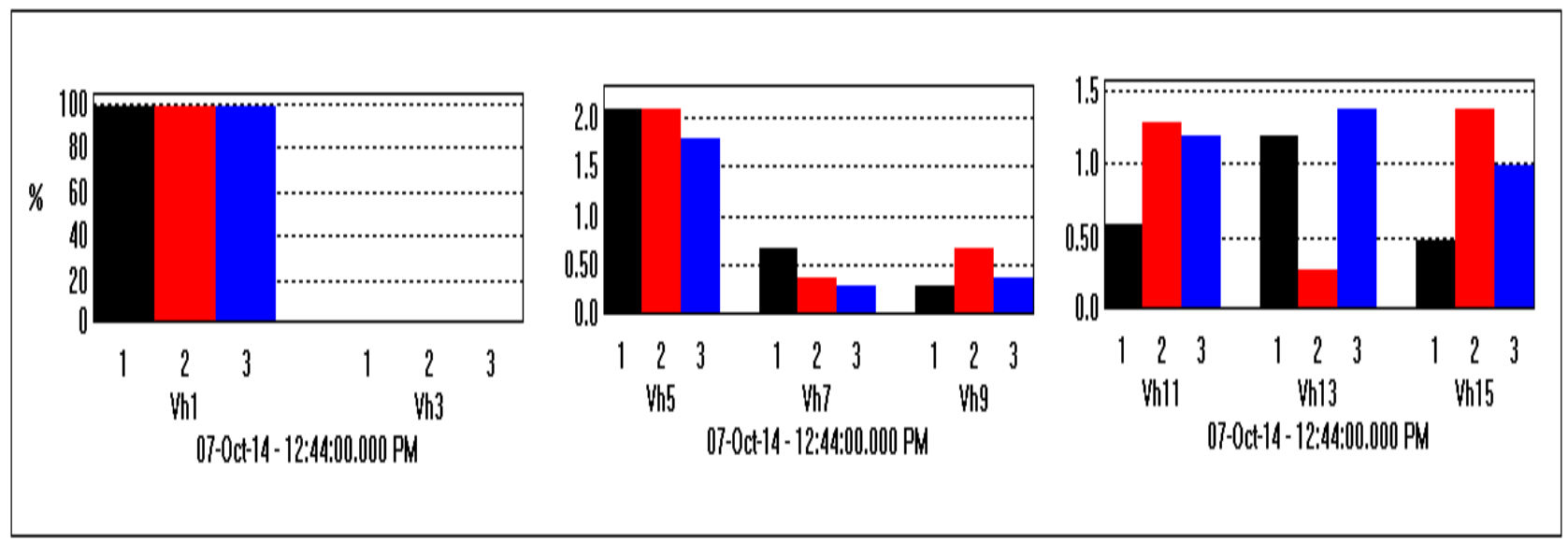

Fig. 4 Voltage THD per phase

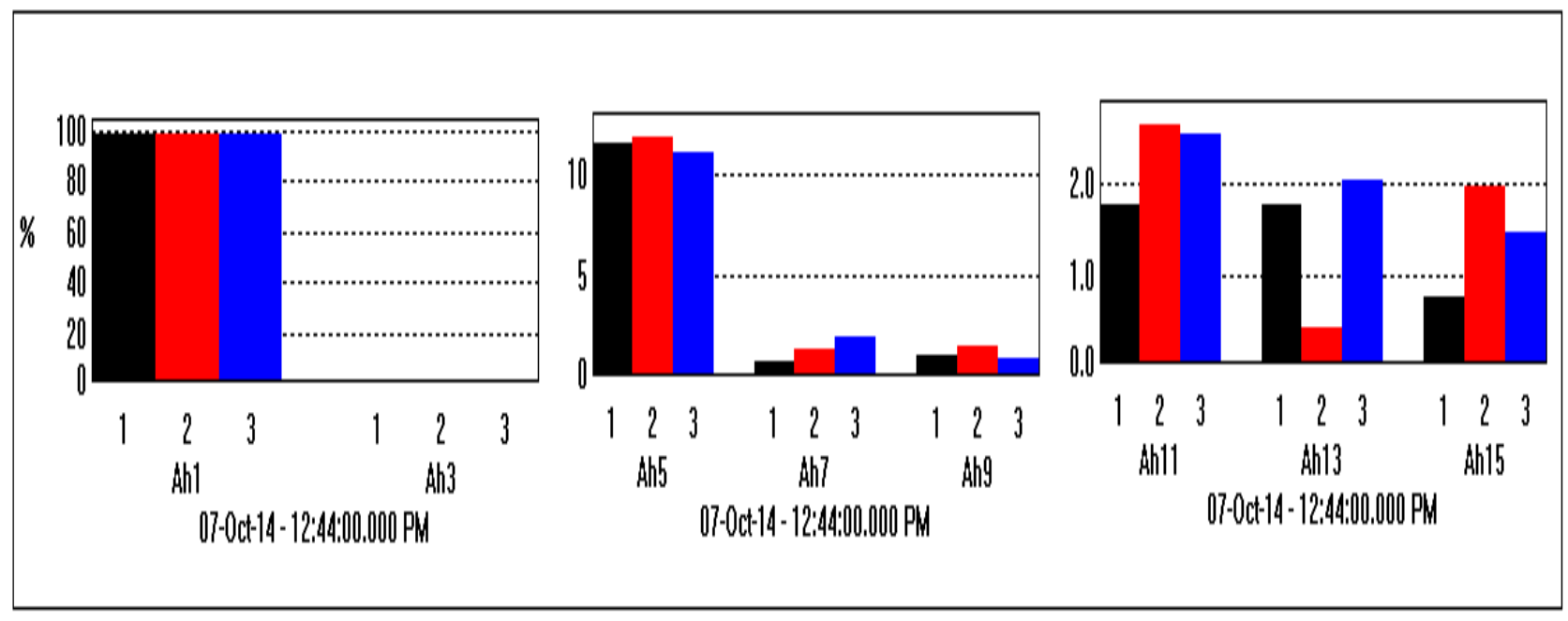

Fig. 5 Current THD per phase 
The Fig 3 shows the power factor at 135KVAR panel. And it is almost -0.47 and at some point it differ very high. As we know as per IEEE standards power factor must be between 0.90 and 0.95 . But in this case power factor is quite less than 0.90 that means the reactive power drawn from supply is very high and it needs to be reduced.[4]

\section{SIMULATIONS}

The simulation is done by considering a System of Rastriya metal Industries pvt. Ltd.

The simulation is carried out using MATLAB/Simulink. In this case the rectifier is used as a nonlinear load and the load connected to RL load of $1000 \mathrm{KW}$.
Block Diagram of the system shown in figure 6

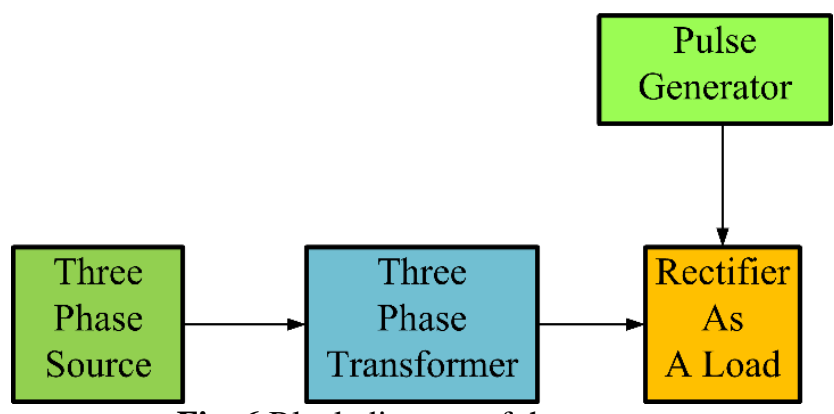

Fig. 6 Block diagram of the system

MATLAB simulation is show in fig 7.

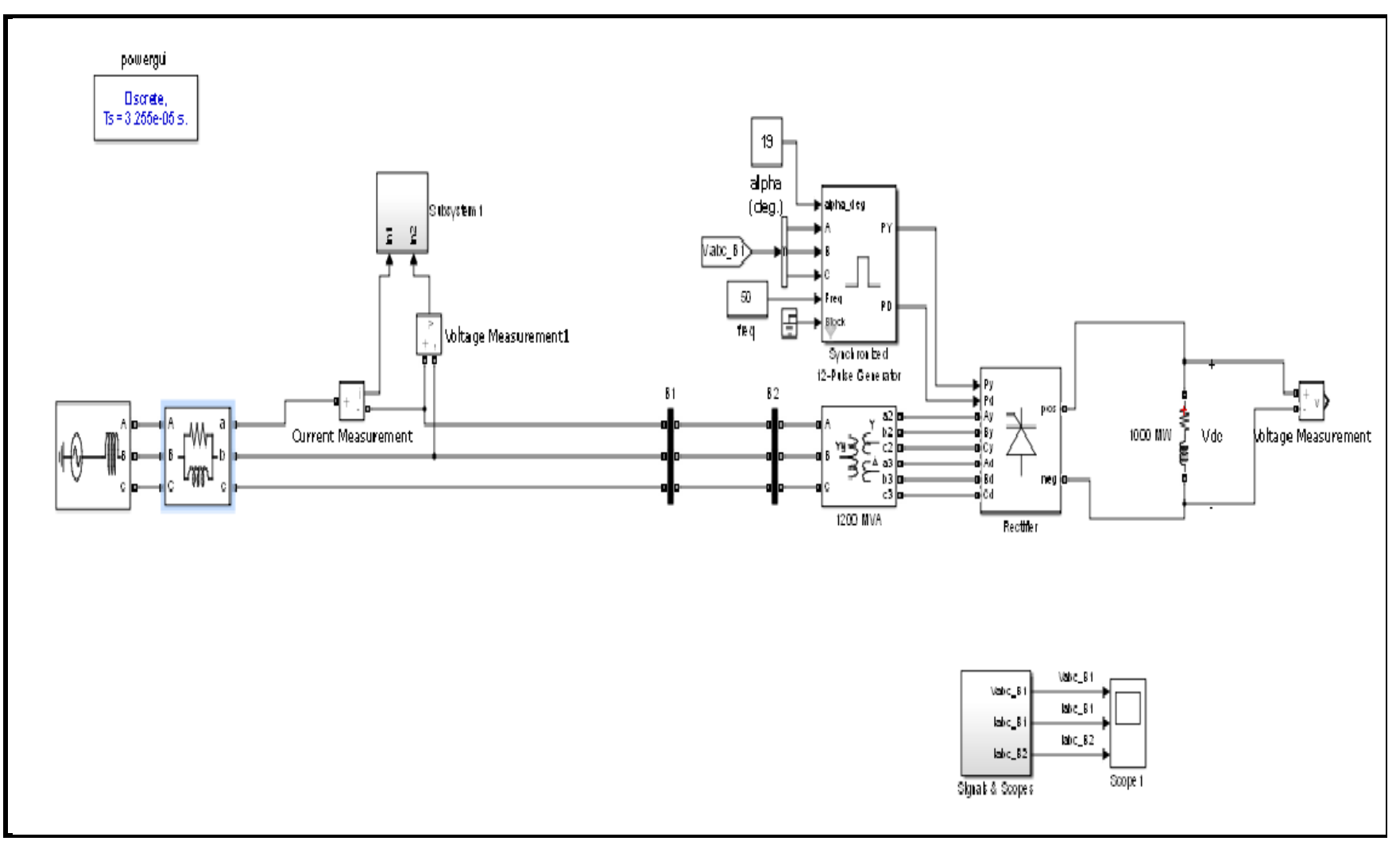

Fig. 7 Simulation of system (MATLAB/Simulink)

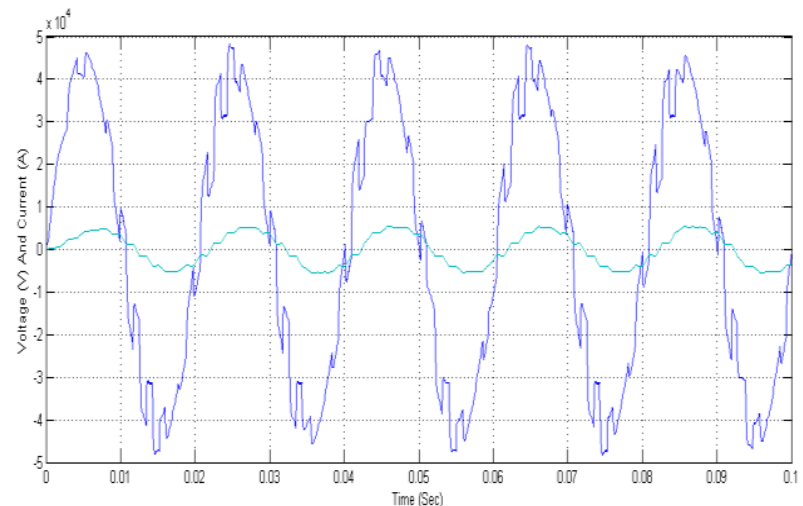

Fig. 8 Voltage and Current Waveform of the system
The power factor of the system is 0.76 , voltage THD is $16.32 \%$ and current THD is $11.16 \%$.

Now simulate the same system with de-tuned filter and improve the power factor of system and reduced the harmonics.

The block diagram of the system with de-tuned filter is shown in fig 9 and MATLAB simulation shown in fig 10. 


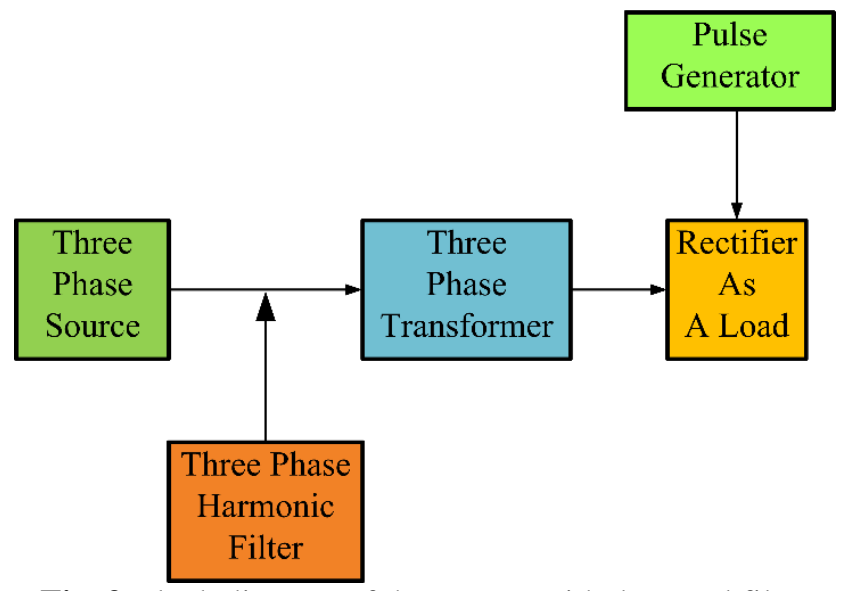

After implementation of de-tuned filter power factor is 0.98 , voltage THD is $3.09 \%$ and current THD is $3.70 \%$

Fig. 9 Block diagram of the system with de-tuned filter

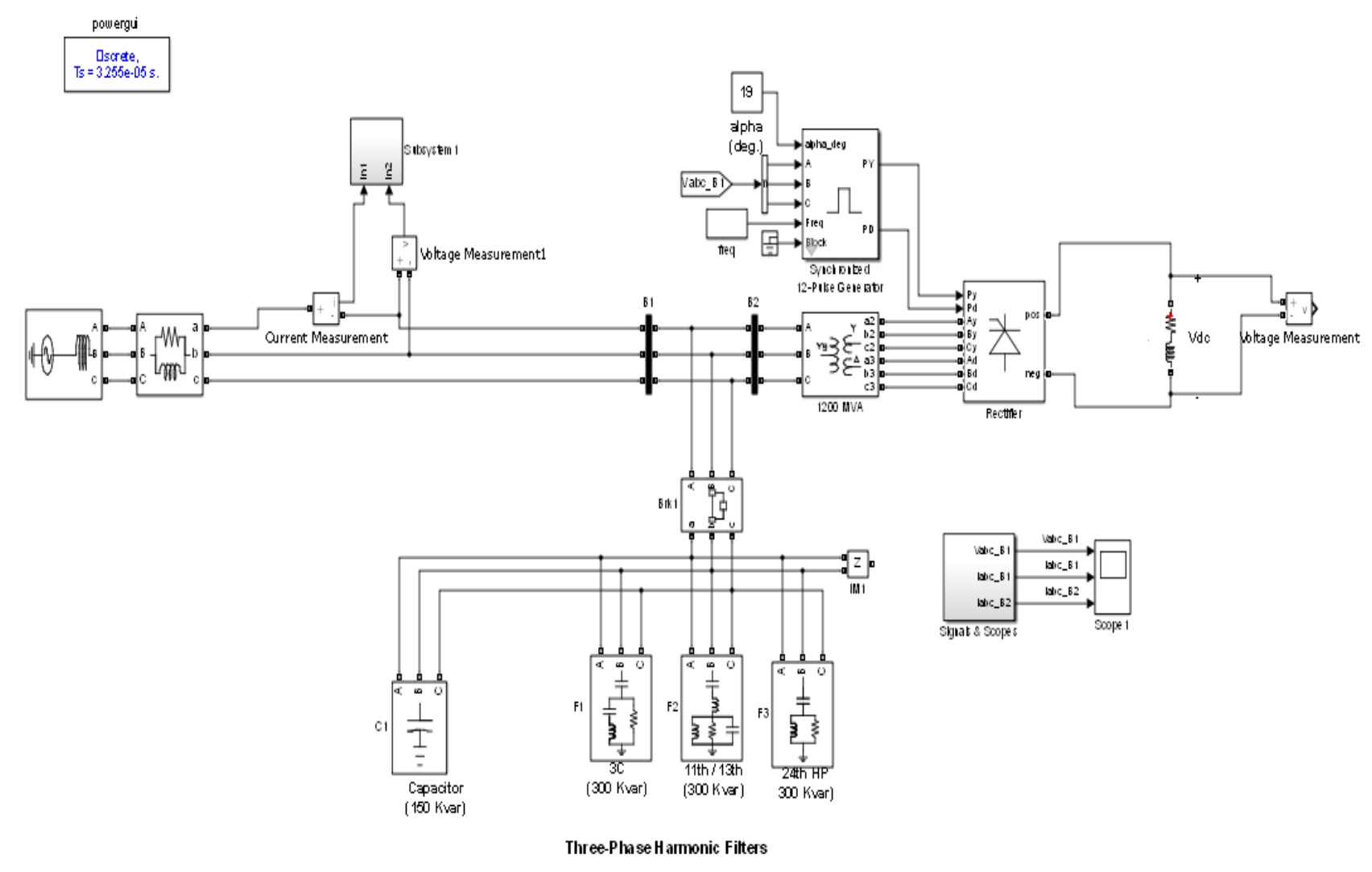

Fig. 10 Simulation of system with de-tuned filter (MATLAB/Simulink)

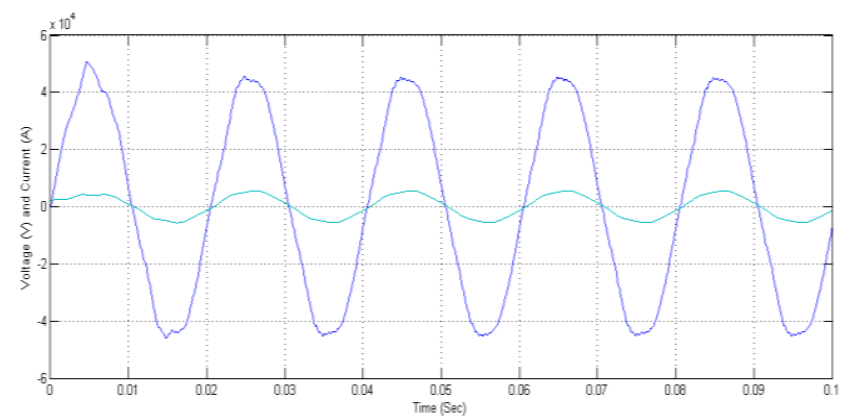

\section{HARDWARE IMPLEMENTATION}

From power quality analysis and MATLAB simulation we decide to make hybrid type power factor correction system and for that APP capacitor(50 KVAr) , 14\% reactor and Thyristor switch modules are used.

Fig. 11 Voltage and Current Waveform of the system with de-tuned filter 


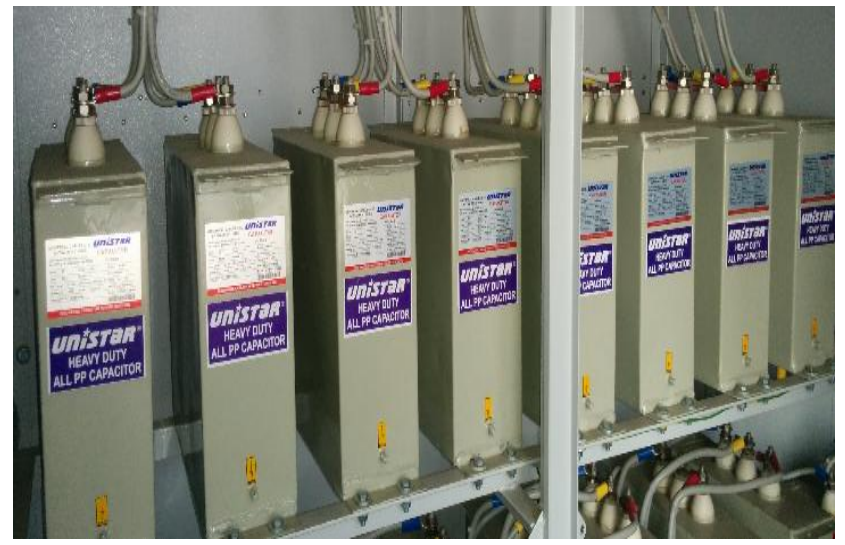

Fig. 12 Capacitors installed in panel

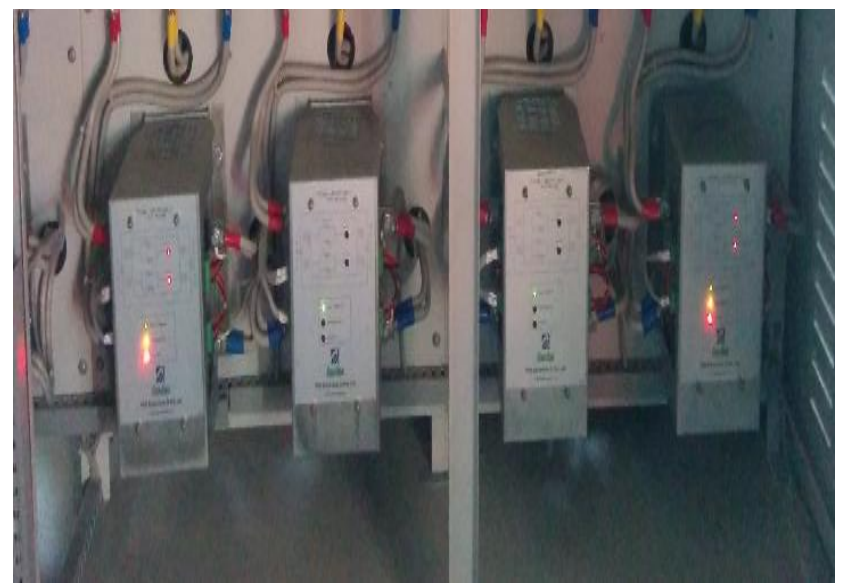

Fig. 13 TSM installed in panel

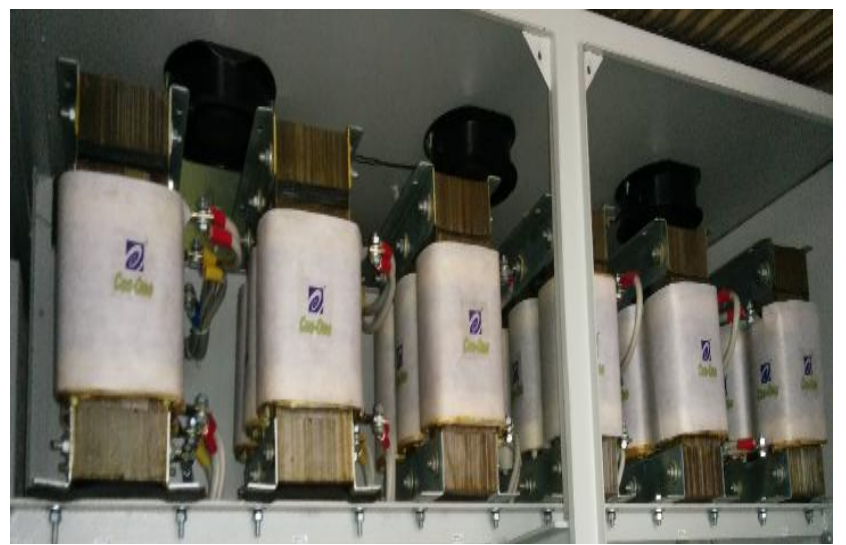

Fig. 14 Reactors installed in panel

After the implementation of all components in panel, panel installed at the industry and then again power quality analysis take place.

Now power factor improve to 0.86 , voltage THD is $7.09 \%$ and current THD is $8.07 \%$

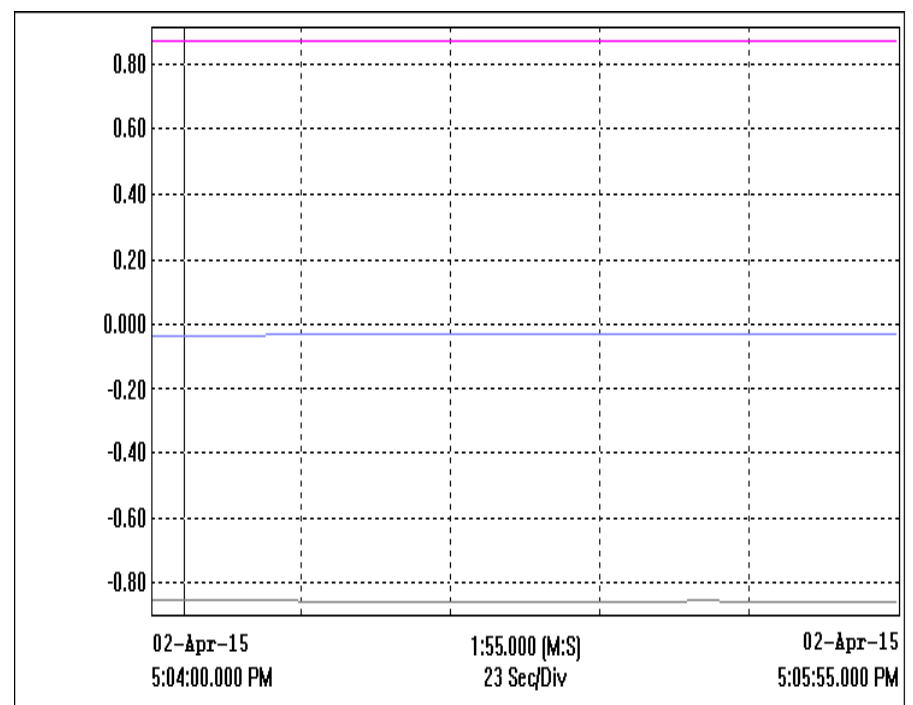

Fig. 15 power factor

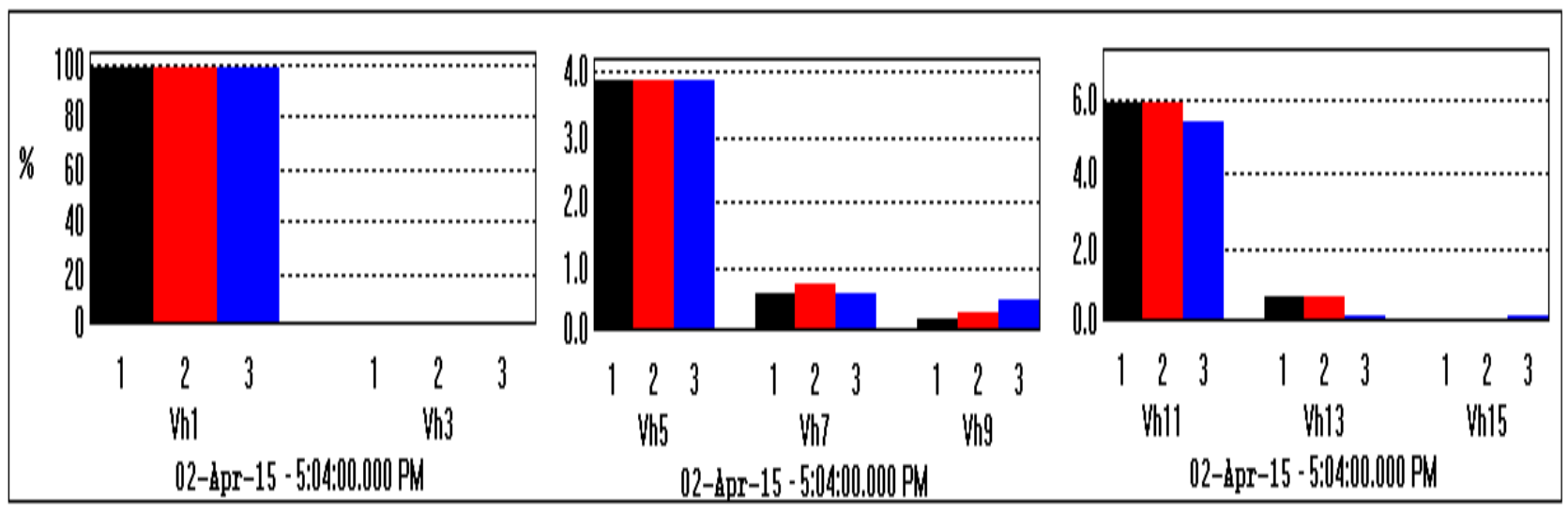

Fig. 16 Voltage THD per phase 


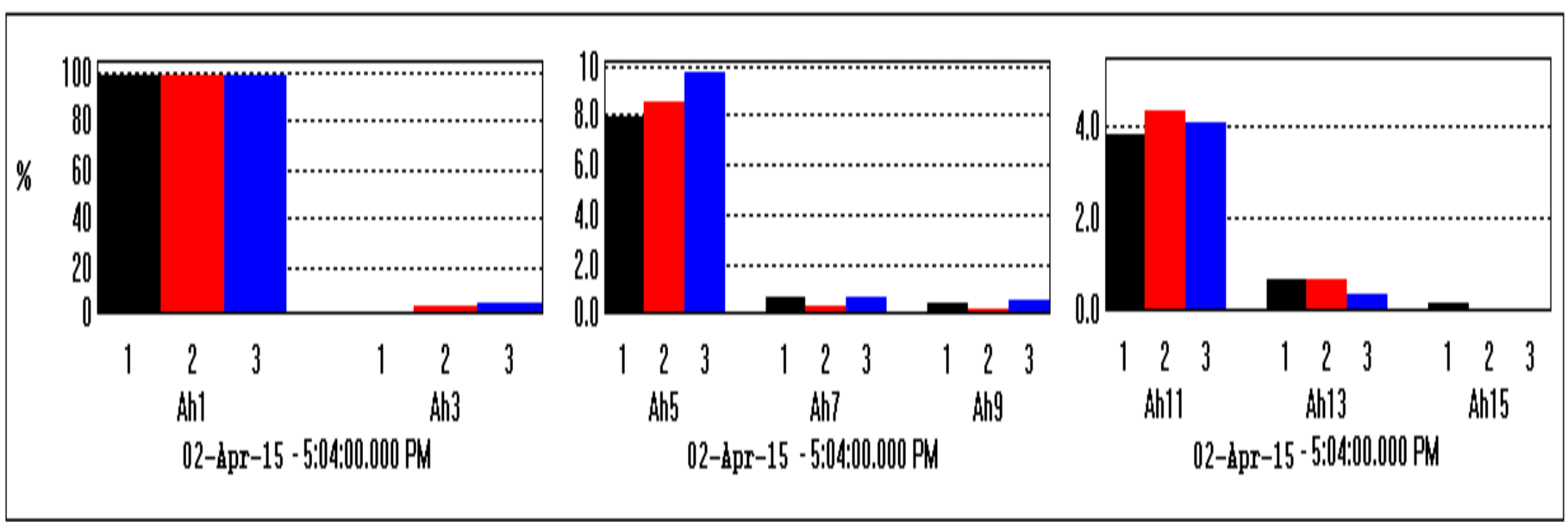

Fig. 17 Current THD per phase

\section{COMPARISON}

Now, comparison of actual system without de-tuned filter implementation, simulation of the system of the same industry and final result after de-tuned filter implementation is carried out.

Table I shows the Comparison of the actual system without de-tuned filter implementation, simulation of the system of the same industry and final result after de-tuned filter implementation .

Table 2: Comparison

\begin{tabular}{|l|l|l|}
\hline \multirow{4}{*}{ Actual System } & P.F & -0.47 \\
\cline { 2 - 3 } & Voltage THD & $\begin{array}{l}14.32 \\
\%\end{array}$ \\
\cline { 2 - 3 } & Current THD & $\begin{array}{l}16.78 \\
\%\end{array}$ \\
\hline $\begin{array}{l}\text { Simulation } \\
\text { (With de-tuned } \\
\text { filter) }\end{array}$ & P.F & 0.98 \\
\cline { 2 - 3 } & Voltage THD & $3.09 \%$ \\
\cline { 2 - 3 } $\begin{array}{l}\text { Final Result } \\
\text { (After panel } \\
\text { implementation ) }\end{array}$ & Current THD & $3.70 \%$ \\
\cline { 2 - 3 } & P.F & 0.86 \\
\cline { 2 - 3 } & Voltage THD & $7.09 \%$ \\
\hline
\end{tabular}

\section{CONCLUSION}

From table II it can be seen that using de-tuned filter of appropriate ratings, harmonics can decrease to very good extent. Harmonics are reduced using Fixed capacitor, 14\% Reactors and TSM and so Among the all harmonics mitigation techniques (Table I) passive filters technique is very conventional and it is proved.

\section{ACKNOWLEDGMENTS}

The authors wish to express their sincere thanks to the PQS Electrolink (I) pvt. ltd, Ahmedabad and Nirma university and Rashtriya Metal Industries Ltd., sarigan GIDC, Vapi for their cooperation in this work

\section{REFERENCES}

[1] Mauricio Areses Hirofumi Akagi, Edson Hirokazu Watanabe. Instantaneous power theory and applications to power conditioning. IEEE press, (Chaper 3 and Chapter 4).

[2] Harmonics - Causes and effects. , David chapman , power quality management, Asia power quality initiative

[3] Harmonic mitigation techniques for the improvement of power quality of adjustable speed drives (ASDs) Domijan, A. ; IEEE 5 19- 1992. Recommended Practices and Requirements for Harmonic Control in Electric Power Systems.

[4] M. Mohseni M. A. Zamani. Damped-type double tuned filters design for hvdc systems. IEEE Transactions on Power Electronics, Vol.9,No.3, May 1994

[5] MALCOLM CAMERON., Trends in power factor correction with harmonic filtering.

[6] Power factor correction and harmonic filtering in electrical plants. Technical Application Papers, ABB

[7] H. Fujita and H. Akagi. Design strategy for the combined system of shunt passive and series active filters. IEEE Transactions on Power Electronics, Vol.5,No.3,June 1991.

[8] Wenjun Wu Jie Li Xiangqian Tong, JunyiXue. Approach of optimal tuning frequency in single tuned harmonic filter. Inter National Conference On Power Engineering.

[9] David E. Rice,"Adjustable Speed Drive and power Rectifier Harmonics - Their Effects on power Systemm components."IEEE Trans on Ind Appl. Vol. IA-22,No.1,Jan/Feb.1986 


\section{BIOGRAPHIES}

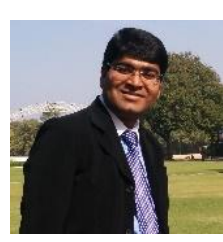

Jeel Contractor received the B.E. degree in Electrical Engineering from C. K. Pithawalla College of Engineering \& Technology, Surat, Gujarat, India, in 2013. $\mathrm{He}$ is pursuing M.Tech in Electrical engineering with specialization in Power Electronics, machines and drives from Nirma university, Ahmedabad,India

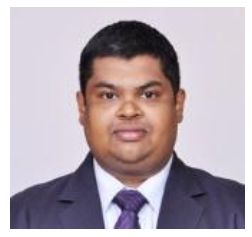

P. N. Kapil received the B.E. degree in Electrical Engineering from Sankalchand Patel College of Engineering, Visnagar, Gujarat, India, in 2007, and the M.Tech. degree in electrical engineering with specialization in Power Apparatus and Systems from Institute of Technology, Nirma University. He has been a member of the Faculty at the Nirma Institute of Technology, Ahmedabad, India.

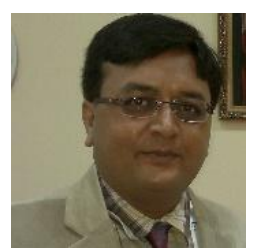

Bhavin V. Shah has done graduation in Electrical Engineering from L.D College of Engineering, Ahmedabad, Gujarat, India, in 1991. Started his career as quality control engineer in distribution transformer company, has spent more than two decades in power quality field with companies like SIEMENS \& EPCOS. He provides solutions for Power factor correction and harmonic filtering solutions for industries. Currently, he is Technical Director of PQS Electrolink (I) Pvt. Ltd, Ahmedabad. 